\title{
The role of building control surveyors and their power in promoting sustainable construction
}

\begin{abstract}
In England, building regulations govern aspects of a building's environmental performance. The Building Control Surveyor reviews designs and on-site construction in order to evaluate, and ultimately certify, compliance with the regulations, but little research has been carried out to investigate the role of these professionals in promoting sustainable construction. A qualitative study was conducted, comprising semistructured interviews with 21 building control surveyors and four key informants from professional bodies in England. The building surveyors initially positioned their power as wholly derived from the regulations, thus constraining their contribution on sustainability to regulation enforcement. However, this stood in contradiction to their recognition of being valued and influential members of the project team. Descriptions of day-to-day activities included sharing common goals with the team, providing guidance based on their knowledge and experience, and developing collaborative relationships. Based on theories of power, these practices may be seen as processes of power. The primary conclusion is that building control surveyors are indeed powerful in the project team, and, with greater recognition of the varied forms of power available to them above and beyond regulatory certification, they could extend their influence in daily working interactions to promote more sustainable construction.
\end{abstract}

Keywords: building control, building regulations, social power, social influence, sustainable construction. 


\section{Introduction}

'It seems to me that power is 'always already there', that one is never 'outside' it" Foucault (1980: 141-142).

"Power is at its most effective when least observable" Lukes (2005:1).

Building control surveyors are part of the construction process on all construction projects in the UK, with the possible exception of very minor domestic works. They are involved in schemes ranging in value from many millions of pounds down to the individual homeowner tackling a do-it-yourself internal re-arrangement. Despite their ubiquity, there has been surprisingly little research involving these professionals. Regulation is frequently seen as a primary means of progress towards more environmentally sustainable construction and building control surveyors have a pivotal role in assessing compliance with building regulations. Therefore understanding their potential for instigating change is essential for the industry to become more environmentally sustainable. The aim of the current study was to investigate the role of building control surveyors (BCSs) with a particular focus on their potential in facilitating environmentally sustainable construction.

\section{Background}

Given the paucity of literature on BCSs, we begin with an overview of their work processes and sector structure. In England and Wales, aspects of a building's performance are mandated by a set of legislative instruments, collectively known as building regulations. These are set out in sixteen parts, including structure (Part A), fire safety (Part B), ventilation (Part F), energy efficiency (Part L) and access (Part M), and two recent additions on security (Part Q, 2015) and broadband access (Part R, 2016). 
The duty of the BCS is to assess compliance with these regulations. The process of building control proceeds either via plans inspection or building notice. For projects with design plans, the plans may be submitted to Building Control prior to commencement of work on site. The BCS conducts an assessment of the plans against regulations, and issues a report indicating compliance, conditional compliance subject to specific modifications or, atypically, rejection. Alternatively, a building notice may be given of intent to begin site work, and builders may begin work 48 hours after notice is given. In either case, Building Control carry out a number of site inspections over the course of construction to evaluate that construction is in line with the plans where submitted and in compliance with regulations. Building Control are required to deliver "a site inspection plan matched to client and project needs" (DCLG, 2014) and thus agree with the contractor or builder at what stages they wish to inspect. This will vary with size and complexity of project and with the level of experience of the site and design teams. Typically, there will be inspections of the groundworks, floor slab, structure and other points at which visual inspection is necessary before work is covered over. Successful compliance results in the BCS issuing a certificate on completion, which can be important for gaining insurance or mortgage funding.

An important aspect of the building control function in England is its structure. The building control function was originally discharged only by local government councils, termed local authorities. From the 1990s however, private firms were permitted to offer building control services, within a strict framework of accreditation. On a regular cycle, building control firms are required to provide a portfolio of evidence of knowledge, capacity, experience, training and insurance which is audited by an accreditation body under the auspices of the Construction Industry Council. Such firms and their qualified inspectors are known as 'approved inspectors'. The building control 
function of assessment of compliance is now carried out by approved inspectors and local authority inspectors. Local authority inspectors have been known as 'building control officers' and the term 'inspector' can be interpreted as referring to approved inspectors rather than those in local authority. For these reasons, we use the term 'building control surveyor' to refer to all professionals in this role.

Research studies which have contributed to knowledge on building control have tended to focus on building regulations, particularly on their effectiveness as legislative instruments. Previous work has examined fire safety regulations (Bright, 2007), general compliance with a focus on health and safety (Baiche, Walliman, \& Ogden, 2006) and, of particular interest here, energy efficiency (Part L) compliance in research exploring sustainable construction (Bell, Smith, \& Palmer, 2010; Cox, 2006; Pan \& Garmston, 2012). There has been consensus in earlier studies that Part $L$ is viewed by BCSs as less important than other regulations (Cox, 2006; Fischer \& Guy, 2009; Williams \& Dair, 2007). Indeed Boardman (2007: 369) argued that Part L was not seen as "worthy of enforcement" by BCSs and Cox (2006:7) concluded that her participants considered Part L to be "trivial". In an extensive review of implementation of Part L 2006 revisions, which were the most radical since energy efficiency was incorporated into building regulation, Bell, Smith and Palmer (2010) held eleven focus groups with over 75 participants from a range of professional groups, including four with local authority building control and two with approved inspectors. They described an extensive range of challenges and recommendations. Amongst these, they noted perception of increased complexity and uncertainty in the regulations, although the participants believed that understanding of Part L had grown. A particular issue for building control was the delegation of responsibility for a thermal model to specialists, who may not have understanding of whether the model represents what is constructed and who have no 
responsibility for comparing the model to the built outcome. Changes made on site which may affect the thermal model were seen as very difficult to inspect, and building control lacked the details, software and knowledge to check amendments.

Looking at sustainable construction more generally, Williams \& Dair (2007) interviewed six BCSs alongside other professionals as part of a study which investigated the achievement of sustainable construction in five case study developments in England. It appeared that local authority building control only was interviewed although this is not clear. The authors defined sustainable construction as including sustainable communities, lower energy use in the built environment, sustainable materials and methods. In the findings, they categorized the top barriers to sustainable construction, which included the failure to consider sustainability on the project (the most frequent issue), and that professionals with regulatory power, such as building control, felt that they had no power to enforce particular solutions .

Studies on research questions beyond regulations have provided perspectives on BCSs seen through the eyes of other construction professionals. Architects and designers have been found to consider BCSs as a barrier to the inclusion of recyclates in construction design (Chick \& Micklethwaite, 2004). Contractors and building performance consultants have questioned understanding of Part L regulations among BCSs (Hamza \& Greenwood, 2009). A particularly bleak image emerged from Fischer and Guy's (2009) study with architects, with some of their interviewees suggesting that BCSs are poorly-paid, under-resourced and lacking in skills (specifically on Part L calculations), with a culture that de-prioritizes energy efficiency. Fischer and Guy also noted perception of increased complexity in the regulations, with performance-based regulations requiring greater interpretive judgements of acceptable solutions. 
However, these are partial perspectives of the wider picture, and differing views on the role of BCSs were discussed within Fischer and Guy's (2009) findings and elsewhere. Good and effective relationships between BCSs and site managers (Baiche et al., 2006) and between BCSs and small builders (Sun, Geelhoed, Caleb-Solly, \& Morrell, 2015) have been noted. Although good relationships between BCSs and builders could lead to an informality that threatens standards (Geelhoed, Morrell, CalebSolly, \& Sun, 2012), flexibility and openness to discussion by BCSs are valued by other construction professionals (Killip, 2013). Amongst Fischer and Guy's (2009) architects, some had experience of productive long-term working relationships with approved inspectors, who effectively became part of the design team. The role of the BCS as enforcer of regulations has tended to be taken for granted in previous studies. Fischer and Guy (2009: 2587) argued that "limited surveillance and weak enforcement" by building control shifted responsibility to the architect - the underlying assumption is that responsibility lies with Building Control to enforce regulatory compliance. However, Baiche and colleagues (2006) were among the few scholars to argue that responsibility for compliance falls to site managers and operatives and that BCSs should be facilitators and certifiers rather than enforcers. In one of the most in-depth studies with building control personnel, and of direct relevance to our research focus on sustainable construction, 59 professionals were interviewed in an investigation of Part L compliance (Cox, 2006). General levels of compliance were seen as high although Part $\mathrm{L}$ was characterized as a weaker area, with complexity an issue. The mechanisms by which BCSs can wield power were briefly outlined. Distinction was made between local authority and approved inspectors. Both can write letters as an initial sanction to draw attention to non-compliance, and can refuse certification. Approved inspectors can refer a case back to the local authority and the local authority can take a case to court, 
although this is rarely done. It is noted that these mechanisms of power are rarely invoked and that "gentle persuasion" is the preferred means of progress (Cox, 2006: 4).

However, it is notew orthy that many of these studies were conducted some time ago and building control regimes have since changed, frequently and extensively. In the interim, the UK Government has enshrined emissions targets in law through the Climate Change Act 2008 and consequently, building regulations Part L have been updated in 2010, 2011, 2013 and 2016, becoming incrementally more stringent. Further legislation on sustainability in construction, such as the Code for Sustainable Homes, has been introduced (and subsequently withdrawn). Lipsky (1980/2010) has argued that policy is in fact made by the day-to-day practice of 'street-level bureaucrats', that is, the individuals with responsibility for implementing government policy. Thus an updated investigation with a focus on building control surveyors, rather than on policy instruments alone, is merited.

\section{Theoretical framework}

The objective of the current research was to explore the role of BCSs with a focus on their potential in promoting environmentally sustainable construction. A qualitative approach was selected as appropriate for an explorative study. In line with recommended practice, we did not begin with a priori theory or expectation. In the analysis stage, we found evidence for the influence that the BCSs wielded and we returned to the literature on power in social interactions. Before describing salient theoretical insights into social power as background for the reader, we briefly define what is meant by the term 'role'

The social role has been proposed as the theoretical construct linking societal structure and individual identity. Sociological role theory conceived of society as a pattern of interactions and relationships in which the individual's social roles permit 
their participation (Stryker \& Burke, 2000). Social roles carry norms and expectations, and identity is formed through their internalisation. An individual's behaviour tends to be congruent with the internalized role. However, the meanings of such norms and expectations are subjective, thus the individual is not determined by a social role but will interpret it and behave within it in individualized ways. In exploring the role of BCSs then, we would expect individualized interpretations of what the role is and how BCS should act.

Despite the focus on weaknesses in compliance in the studies involving BCSs cited above, empirical findings show generally high levels of compliance with building regulations, demonstrating that the role of the BCS is by and large successful (Baiche et al., 2006). However, the implicit assumptions around power as enforcement and the very limited discussion of how BCSs achieve compliance within interactions with other construction professionals ignore long-standing knowledge on the nature of power and influence in social interaction. Bertrand Russell (1938) argued that power is fundamental to social relations, a perspective echoed by Foucault. The opening quotations above point to the necessity of a theoretically-informed lens in order to examine power and influence - power may not be readily 'visible', quantifiable or measurable but theoretical understandings of manifestations of power offer an analytical framework with which to examine empirical data. Problematically, theoretical inquiry into the subject of power has emerged from multiple perspectives and no single perspective prevails - different approaches offer different insights. Here we briefly review contributions on types or bases of power, and the processes of power, as particularly useful in the analysis of our data. A review by Brauer and Bourgis (2006) clustered these into four levels: (1) socio-political or institutional (e.g. Foucault, 1980; Lukes, 2005); (2) intergroup (e.g. Tajfel \& Turner, 1979; Turner, 2005); (3) 
interpersonal (e.g. Fiske, 2001) and (4) intra-personal including individual cognitive processes (e.g. Fiske, 1993; Keltner, Gruenfeld, \& Anderson, 2003). Multiple perspectives on power have led to multiple understandings of how power and influence may be defined. Definitions range from considering power and influence as equivalent processes (Simon \& Oakes, 2006), to power as the ability to control outcomes alongside influence as the process of producing change in others (Fiske \& Dépret, 1996), to power as a capacity, but not necessarily a process (Lukes, 2005). The problem of definition is compounded by lay implications of the terms. Here, due to its clear distinction between capability and behavioural outcome, we adopt the definition of power of Lukes (2005), Raven (1993), Melamed and Savage (2013) and others, as the capacity to change others' behaviour, and influence as the process of changing it. Thus power is the potential to achieve change whereas influence is the enactment of that capacity. By implication, power may be possessed by an individual or group but not deployed.

Previous work on power has referenced sources or bases of power. Within the construction literature, Fellows and colleagues (2009) noted wealth and knowledge as two overt power bases, and also referred to structural power. Bresnen (2013) proposed a categorisation into instrumental power (e.g. financial, knowledge) and symbolic power (e.g. norms, culture). Although useful, such categorisations only partially represent a more comprehensive classification of power proposed by French and Raven (1959) which remains predominant in social research today (Dorrenbacher \& Gammelgaard, 2016; Guinote \& Vescio, 2010). Of the bases of power proposed in French and Raven's (1959) model, the most easily recognized are those of reward, coercion and legitimacy. Power stemming from the ability to reward is self-evident and coercion is its complement - the power to punish. Threats and rewards may be real, as in the power to award or deny certification of building compliance, but may also be interpersonal - 
personal approval or disapproval by someone perceived as important to the individual also function as threat or reward. Legitimate power arises, amongst other sources, from a structural relationship (cf. Fellows et al., 2009), thus the position of building surveyor carries formal legitimate power, based on its legislative role, to query or challenge others in the design team. Other bases of power are those of expert and informational power, to which Bresnen (2013) referred as instrumental power. Indeed, Hardy and Clegg (1999:35) argued that, within and constitutive of organisational structures, "knowledge is power". Expert power lies in the tendency for people to follow the advice of those they consider experts, in the assumption that the expert has greater knowledge. Informational power relies on access to information or reasoned argument. Thus French and Raven's model of social influence proposes five bases of power which may be available to BCSs: reward, coercion, legitimacy, expert and informational. While the bases of power offer valuable insight, power is not simply a possession or characteristic of the individual or group. Power is embedded within wider contexts, as the review of Brauer and Bourgis (2006) elucidated. Power is interwoven with other relations and subject to negotiation within reciprocal relationships (Foucault, 1980). Emphasising its fluid nature, Bresnen (2008) argued that construction professionals reproduce patterns of power in their daily practices.

Moving from the institutional to the inter- and intra-personal, sociopsychological insights point to ways in which processes of power relations may play out. Reid and Ng (1999) investigated how language can create power, while acknowledging that power is not generated through language alone. Cialdini's (1993/2007) seminal work on influence elaborated mechanisms of reciprocity, liking and commitment as well as authority. Simon and Oakes (2006) proposed an identity model of power, in which they argued that consensus, in balance with conflict, can be 
important in power dynamics and that power works through identity processes. That is, it is through shared identities that influence is wielded. Thus a BCS may influence an architect, for example, through a common identity as built environment professionals. Fiske (1993) demonstrated that realisation of power affects social cognition, that is, how social interactions are understood. Powerful individuals perceive and pay attention to different aspects of their social context than the powerless. Keltner and colleagues (2003) argued that power activates approach behaviour, and lack of power triggers behavioural inhibition, that is, people who feel powerless are less likely to act. The processes of power then include identity and differential cognitive processes of perception, attention and motivation.

Having summarised the limited literature on BCSs and salient theoretical insights, the research question for the present study was: What role does the BCS play in construction and what is the potential of the role with respect to promoting sustainable construction?

\section{Method}

In order to explore the role of building surveyors in depth, a qualitative methodology was adopted. The objective was to gain a broad and nuanced account of how building control surveyors themselves perceived their role. Semistructured interviews were conducted with twenty-one building control surveyors and four senior representatives of relevant professional bodies (the Chartered Association of Building Engineers, the Chartered Institute of Building, the Association of Consultant Approved Inspectors and Local Authority Building Control). Eleven of the participants worked in local authorities and ten in approved inspector businesses. The majority of participants were recruited by direct invitation. For the approved inspectors, a list was compiled of all approved 
inspector organisations, and for local authorities, a list of councils in England was consulted. A small number of participants volunteered by responding to a notice on the Planning Portal website. Both businesses and local authorities were selected to ensure a spread of representation across England. No other selection criteria were applied. The study was described as focusing on the role of building control in general. The interviews were conducted by the second author, by faceto-face or phone to enable a broader geographic spread. They lasted approximately one hour and were audio-recorded and transcribed verbatim. The phone interviews, conducted with two of four key informants, six of 11 local authority surveyors and five of 10 approved inspectors, tended to be shorter than those conducted in person, but no other pattern of difference was found.

The interview schedule was designed to gain understanding of the processes of the job of building control, its constraints and opportunities (see Appendix 1A). The interview began with general questions on staffing and workload, type of project and a 'typical working week'. The questions then explored the main objectives of the building control role, the participant's career path into the sector, their motivations and strengths and the strengths of their colleagues. Participants were asked to describe the job of which they were most proud, a technique adopted from the process of appreciative inquiry (Watkins, Mohr, \& Kelly, 2011) - a narrative of a particular job can illustrate much about processes, relationships and priorities. Finally, the topic of sustainability was introduced: participants were asked to define their understanding of this concept, to describe the role of building control in sustainability and to suggest what their role could be. For the key informants, the interview schedule was modified to ask more general questions on the background to changes in building control over recent decades in place of personal career paths (see Appendix 1B). 
Thematic analysis was conducted on the data, following the guidelines of Braun and Clarke (2006). In this method, the transcripts are read and segments of interest coded. The coded segments are clustered into subthemes and then themes, checking back constantly to the data to ensure completeness and accuracy. Themes are noted as they occur throughout the text, and are not necessarily linked to specific questions in the interview schedule. The analytic approach minimized the effects of social desirability (the tendency to present oneself in a favourable light) as analysis was based not only on answers to specific questions but also on descriptions of the day-to-day job and responses to other general questions. This form of analysis moves beyond description of participant responses and the 'face value' of the text and applies a critical analytical lens. It requires stepping back from the data to explore patterns and contradictions, and to seek insights from the literature. In keeping with recognized standards of rigour and validity, data abstracts are presented below to demonstrate transparency and to allow the reader to evaluate the appropriateness of the analysis.

\section{Findings}

As noted above, an overarching theme of power emerged in the analysis and we chose to focus on its two subthemes for discussion in this paper: (1) ensuring basic compliance with legislation and the perceived limitations of the role; and (2) acknowledgement and processes of influence. Verbatim quotations from participants are indicated below by number to protect anonymity (e.g. AI-1 Approved Inspector no. 1; LA-5 Local authority building control officer no. 5; KI-2 Key informant no. 2) and the themes applied equally to approved inspectors and local authority building control. Although our research focus was on environmentally sustainable construction, this is not a separate element of BCSs' work. The broader picture of how BCSs operate in their day-to-day activities is necessary alongside examining aspects relating to sustainability. 
The term 'sustainability' has been critiqued as ill-defined (Murtagh, Roberts, \& Hind, 2016). To ground references to sustainable construction in the analysis below, we begin with a brief summary of responses when participants were asked what they understood by "sustainable construction". Most participants referred to energy efficiency and thermal performance. Some referred to flooding, biodiversity, water efficiency, waste and materials. Several saw sustainability in terms of durability, linking the term to high quality, flexible buildings that were useful to their occupants and to society over time. A number spoke about the bigger picture and global context of environmental protection. For most participants then, there was a holistic understanding of sustainability in construction, not restricted to the aspects addressed in current building regulations. To them, it meant not only energy efficiency and consideration of carbon embedded in materials but also buildability, economic and social sustainability, recycled materials and renewable energy, responsible sourcing, and transport of materials.

\section{Basic compliance with legislation and the perceived limitations of the role}

Asked to describe the role of the BCI, the key informants referred to its overarching contribution to society: "it's to provide safe, accessible, sustainable buildings...for the benefit of society really" [KI-1] and this represented the view of most participants, for example "putting it quite bluntly, it's to stop people dying" [LA2]. However, along with the key informants, many participants initially described their role as explicitly bounded by legislation: "Our role is to ensure that the building, as built, complies to the minimum standards as laid out under the building regulations" [AI-5]. They clarified that the building control surveyor's perceived role does not include design. Although they can exercise judgement and consider novel solutions, they cannot instruct changes that have cost implications. Indeed, most saw decisions as 
being driven by others: "We're not really a decision maker that...can make a lot of difference ... Contractors and clients and designers have more of a role to play" [LA-4]. This deferral to others carries a sense of powerlessness. A number perceived the role of BCS to be overlooked and some explicitly stated their feeling of lack of power behind the role:

We have a role to play, but we haven't a great role, we're not really a decision maker that, I don't think, that can make a lot of difference...I don't think we have the power behind us to [make construction more sustainable] [LA-3].

With respect to sustainable construction, some participants felt that their fundamental responsibility was that of compliance with Part L, and more generally to implement government policy, seeing no involvement without the existence of legislation: "The only way building control could make [construction more sustainable] is to get it within the legislation as set standards, otherwise we can't really enforce anything" [AI-1].

In their initial responses then, the sense from many was of the limitations of their role, it being closely aligned to building regulations and with power only to assess (minimal) compliance. These responses recognized only the structural (Foucault, 1980; Lukes, 2005) or legitimate (French \& Raven 1959) forms of power - they speak to a role wholly constrained by its socio-political position and associated instrument, the building regulations.

Given the positioning of the perceived role as dependent on the regulations, the views of the participants on legislation is important. The previous quotations illustrate a general assumption from the interviewees that additional legislation is an essential prerequisite to improvements in the industry. Nonetheless, there were many comments 
on the inadequacy of existing and previous legislation. The lack of drive for improvement from the current government and a policy direction of getting rid of regulation was noted.

In order to assess the relative priority of environment-related provisions, participants were asked if all regulatory parts were of equal importance. There was consensus that compliance with all parts were required but that primary attention may be paid to some provisions over others. As Participant AI-2 explained: "We can't sign a building off unless we're satisfied that every single building regulation is at a satisfactory standard, but naturally, you get drawn towards certain regulations because of the impact they have". For most participants, fire and structural safety were the parts that were first mentioned although a few also referred to Part L on energy efficiency as high priority. This suggests a somewhat complex take on the regulations by BCSs: the experience of an implicit hierarchy of importance influenced by risk and tangibility alongside recognition of the equal statutory footing of all provisions. In reality, as one participant noted, it is highly unlikely that relative priority between regulations would be traded off, and there was consensus of the requirement for compliance with all parts of the regulations. This stands in partial contradiction to previous work which described a culture of de-prioritising energy efficiency (Cox, 2006; Williams \& Dair, 2007).

The issue of Part L compliance was not simply a lack of interest or motivation on the part of building control, as suggested in earlier work (Boardman, 2007). Several people explained that Part L had become increasingly complex: "You go to Part L and I'm sorry, but you need to be a scientist to really understand what it's telling you" [LA8]. Due to the skills required, SAP calculations are done by specialists and BCSs can only check that the relevant information had been completed. On site, visual inspection is of little use as different levels of insulation in different parts of the building can be 
traded off to ensure an overall $U$ value. Whereas for most regulations, BCSs can inspect components on site, for Part L, component checking is not sufficient. Any changes from the design specification, however slight, must be checked back to the overall thermal model, which may need to be recalculated by a specialist using dedicated software.

In summary, the responses demonstrated complex issues with Part L. Although there was a widespread assumption that legislation is necessary to drive improvement, the participants described inadequate legislative approaches, including Part L.

\section{Acknowledgement and processes of influence}

In contradiction to the initial description of the BCI role as circumscribed within structural legislative boundaries and often overlooked, participants went on to provide examples of their influence, acknowledged by others and as everyday lived practices.

The key informants from the professional bodies noted the influence wielded by the BCS. One explained:

That influence is real... the small to medium sized contractors, they will defer to a building control officer for the simple reason that they want to get a building built ... and they will give him his place [KI-3].

Participant AI-8 described both significant influence and its invisibility,

For the industry, we have a huge impact on the built environment, huge - and I always say this - we're the people that no-one notices, so when the buildings win their RIBA prize, we never get a mention [AI-8].

This extract illustrates Lukes' (2005) argument in the second quotation with which the paper opens, that effective power may not be visible.

Although overall few of the participants spoke openly about their influence (discussed further below), several described their importance to the project team, for example: 
It's quite rewarding to sit in a design team meeting where you've got various designers around the table and you can actually help and support them in getting their design right and they value you as a member of the team $[\mathrm{AI}-3]$.

Here, the participant refers to the acknowledgement of influence: to be valued as a member of the team is to be recognized as influential. Further, it is recognition of common goals, the basis for social influence proposed by Simon and Oakes (2006). A number of the participants could see their knowledge appreciated and recognized within the project team: "[the client] respects our knowledge and specialismand how we understand technology" [AI-10]; "people will respect you if they think you have the knowledge" [LA-7]. Others explicitly noted their perceived role had increasingly involved education of other professionals on the project and "pass[ing] the information on to builders and designers" [LA-2] as regulations and technology have become more complex and fast-changing. Further examples were offered of the BCI saving the client money and meeting higher levels of sustainability through discussions around the design. These examples, unrecognized by the participants, speak to power based on knowledge, information and expertise (Bresnen, 2013; Fellows et al., 2009; French \& Raven, 1959). The knowledge that BCSs brought to bear in the industry was evident throughout the discussions. The career paths taken to become an accredited BCS required academic qualification for most, professional training and practical experience, as well as continuing professional development. From the descriptions of their day-today interactions, there was evidence that some BCSs brought "extensive depth of knowledge" [AI-5] to their work.

Awareness that their expertise was valued by others stood in contrast to the common description of the limited nature of the role. However, the descriptions of 
everyday interactions provided evidence of the processes through which the BCIs enacted influence. First, in explaining their perception of the role of the BCI, a number of participants positioned the goal of assisting the design team and client as a primary objective:

Our primary aim is to get the best possible outcome for the building in terms of the client's wishes and the design team's wishes, at the same time as achieving the highest level of compliance... we have two goals [AI-8].

Many participants described their role as helping the client "get to a proper end result" [LA-10]. As discussed above, sharing common goals implies a shared common identity which facilitates mutual influence within the team (Simon \& Oakes, 2006). Second, several described how their expertise was needed to interpret "grey areas" in regulation, where the requirements were not straightforward, and how clients depended on their help to do so. The argument of knowledge as power (Hardy \& Clegg, 1999) is exemplified in this extract: "A lot of them are not actually conversant with the regulations, so ...we also almost have to design some of the aspects of the project for them" [LA-5]. Third, the majority saw their role as including the provision of guidance and advice. Most offered technical consultation at a pre-submission stage, to members of the general public as well as to other construction professionals, and their advisory services continued from the early stages of the project right through to on-site work. This knowledge was not limited to the regulations but extended to offering suggestions for achieving compliance on potentially difficult projects such as listed buildings, problem solving, proposing alternative solutions and making judgements around how the regulatory requirements could be met. In part, the knowledge was based on experience. Again, the examples of advice and guidance, universal amongst the 
participants, speak to power through knowledge (Bresnen, 2013; Fellows et al., 2009). Fourth, the advisory role required sophisticated communication skills, comprising negotiation, advocacy, persuasion, "advising, consulting, negotiating, compromising sometimes" [LA-3], "cajoling, negotiating and steering" [LA-7]. The choice of language (Reid \& Ng, 1999) and other processes of persuasion (Cialdini, 1993) are implied. Fifth, building a good relationship facilitated efficiency and consistency in their services. Further, good rapport meant being seen as a valued member of the team, and feeling part of the team was important to the BCSs. Some participants explicitly contrasted their usual approach with an earlier, stereotypical role of 'police officer': "We need to advise and be advisory because the world has changed and customer expectations have changed. Nobody, a householder, or whatever, will tolerate anybody wielding a big stick from the public authority" [LA-3]. Here the participant makes reference to what is termed coercive power in the social power model (French \& Raven, 1959) and notably, the reference relates to the ineffectiveness of this power base. Thus the everyday interactions of the BCIs displayed processes of influence: sharing common goals with designers and clients, possessing expertise needed by others, offering advice and guidance based on knowledge, deploying persuasive rather than authoritarian skills and developing rapport.

In contrast to the emphasis from the majority on the constraints of their position, some participants showed a broader vision of the potential influence of the building control role. Noticeably, a few did not accept the limitation of minimal compliance with regulations, speaking instead about contributing to higher quality in construction: "I think [the role of building control is] to support the construction industry in getting the quality of building construction as high as possible" [AI-3]. Others described being proactive in their approach within the limits of ensuring compliance "My role is to ensure 
compliance, that doesn't mean I can't be pro-active and help in achieving their goals" [AI-8]. As proposed in sociological role theory, a social role does not determine a person's behaviour and individuals subjectively interpret meanings of the role (Stryker \& Burke, 2000)

Some participants noted the wider role of the building control sector, contributing to British Standards for example, and others saw the potential for this to be expanded and to include input to regulations. There was discussion of driving the industry through taking expert positions on policy groups, and advisory panels and, at the working level, "encouraging builders and fellow colleagues to go beyond the minimum" [LA-2] as well as advocating building-wide innovation such as off-site construction. With respect to sustainable construction, the participants also spoke about advising, guiding and advocating more energy efficient buildings. Several saw the role of building control as raising awareness and educating clients and other construction professionals.

When asked about the contribution that the building control professional could have, participants proposed multiple ways for the sector to facilitate progress of sustainable construction. Reference was made to the ability of building control surveyors to "push the boundaries" $[\mathrm{AI}-5]$ and to facilitate the introduction of alternative technologies and methods; to apply their knowledge for more holistic solutions; and "to encourage people to think" [LA-2]. There was recognition of the potential to encourage others on construction projects to set and achieve higher standards with respect to the environment and generally "to promote good practice in terms of build and materials" [AI-10]. One key informant felt that building control had the potential to influence the industry in general and could encourage development of government policy. Another BCS described his efforts on a flagship project, where "we 
invite people to come and build houses, for example, which go beyond the minimum, so...we could actually demonstrate excellent practice - not just good practice, but excellent practice" [LA-2]. His aim was to educate the public to demand better energy efficiency. Thus, despite near universal recognition of the limitations of institutional power of their role, a number were actively influencing others in the industry and looking for further ways to do so. Despite the formal constraints on the BCS's authority, these surveyors had found ways to deploy their knowledge and experience to have a positive impact on construction projects.

\section{Discussion}

In our analysis of interviews with twenty-five building control professionals in England, we critically assessed their claims that their role in sustainable construction is based on, and limited to, building regulations alone. The building regulations offer BCSs a clear basis of institutional power (Foucault, 1980; Lukes, 2005), which the participants readily acknowledged. However most participants perceived their role as wholly limited by the content of building regulations, overlooking other forms of influence. This discursive position neglects the processes by which BCSs in fact operate. We found evidence in their responses demonstrating power in their perceived role and influence within the project team. The participants spoke not only of their contribution in projects but of being valued members of the team, that is, of their contribution and thus influence being acknowledged by other construction professionals. There were examples of their knowledge saving the client money and increasing the levels of sustainability attained. Beyond educating others within individual projects, some BCSs contributed to national standards, were called upon as experts within policy groups and advisory panels, and were involved in voluntary 
'flagship' initiatives demonstrating high quality and sustainable construction. Such examples are evidence of power and influence wielded by the BCS in their working life.

Several processes by which influence was deployed were identified in the participants' responses. Their emphasis on sharing common goals on the project showed a shared identity within the team. In the identity model of power (Simon \& Oakes, 2006), a shared identity places the individual within the in-group and permits consensual and productive mechanisms of power. In contrast, an individual who positioned him/herself as outside the team would require coercive methods to deal with conflicts of power, perhaps wielding the "big stick" of authority. The identity model usefully distinguishes 'power to' from 'power over' and elaborates the identity processes involved in 'softer' forms of power (Raven, Schwarzwald, \& Koslowsky, 1998). Although Simon and Oakes (2006) argued against a dependence paradigm, in which power is based on possession of a valued resource, the evidence here was for the importance of the BCS's knowledge and expertise as a basis, in part, for their influence. Knowledge as power has been argued by construction scholars such as Bresnen (2013) and Fellows et al.(2009), and socio-psychological/organisational scholars such as French and Raven (1959) and Hardy and Clegg (1999). Interpreting the regulations and drawing on their expertise and knowledge meant that the BCS routinely is involved in problem-solving, identifying potential problems and suggesting alternative solutions. However, theoretical insights into power as dynamic rather than static, and negotiated within interactions (Foucault, 1980) make clear that a resource such knowledge per se does not necessarily grant influence - it depends on the mechanisms through which it is wielded. The findings showed evidence for language (“cajoling, negotiating") and interpersonal skills (building rapport) as processes of influence and it is likely that other 
skills are routinely deployed (Cialdini, 1993). For example, although not mentioned directly by participants, the role of trust may be a factor contributing to influence.

The perception of participants that they contribute to construction design is echoed in work by Imrie and Street (2011) on architects and building regulations. These scholars point to design of the built environment as emerging the daily activities of a network of actors, that involve negotiation and disputation, and in which regulations play a part. Within the network, they describe mutual influence, echoing the identity model of power (Simon \& Oakes, 2006) and the Foucauldian view of power as an interactive and reciprocal relationship. Such theoretical perspectives support the argument of Hughes and Hughes (2013) that sustainable construction bestrides professional domains and requires collaboration. Fischer and Guy (2006) proposed that architects could perform an integrator role to achieve greater levels of sustainability and there is an argument that BCSs are similarly positioned with an overview of the project. In fact, some participants here argued that they were better placed than architects in view of their regular and detailed site visits. Despite the allure of an integrator role, this would pass responsibility to a single professional on the team, potentially undermining the shared goals and shared identity on which consensual and productive power relations are based. Whilst acknowledging that influence may positive or negative, theoretical understanding of power as a means of "getting things done, or with getting others to do them" (Barbalet, 1985:538) emphasizes the collaborative nature of human enterprise. While acknowledging the view that an overly close relationships between BCSs and other professionals could lead to an informality that threatens standards (Gellhoed et al., 2012), weecho the argument of Hughes and Hughes (2013) that more sustainable construction depends on collaboration, as demonstrated by the BCSs in our study. 
Given the BCS's perceived role as possessing influence on the bases of expertise and information as well as legitimate authority and ability to sanction, what does the literature suggest are concomitants and consequences? A position of power is related to a perception of self-efficacy and control (Haidt \& Rodin, 1999) while perception of powerlessness can lead to deferral to others' expectations and situational constraints (Galinsky, Magee, Greunfeld, Whitson, \& Liljenquist, 2008). Higher power is also associated with greater freedom of action, and lower power with more constrained behaviour and attention to threat (Keltner et al., 2003). Both high and low power responses were in evidence in the data. The BCSs who described the potential of the role for pushing the boundaries and changing how people think were more aware of their potential influence, and those who felt that their role afforded some influence were more likely to believe that they could effect change. Furthermore, they were more likely to possess a stronger goal orientation and more likely to take action (Magee, 2009): the participant who was involved in a flagship project to demonstrate excellent practice is a good example of this process, together with the participants who described being proactive in their work. Conversely, those who felt constrained within their role ascribed influence to others (cf. "contractors and clients and designers have more of a role to play") and tended to argue that they were wholly limited by the regulations and ineffectual without further legislation, taking a passive and powerless position.

Considering the relationship between BCSs and Part L of the building regulations, the current study contrasts with earlier research (Boardman, 2007; Cox, 2006; Williams \& Dair, 2007) which argued that Part L was seen as less important by BCSs. The participants in this study were clear that all regulations were important. Even if some appear to be primary, the participants noted that compliance with all relevant parts must be achieved. As the earlier studies were completed some time ago, it is 
possible that understanding of the importance of Part $\mathrm{L}$ has developed in the interim as new and more stringent versions have been implemented. The passage of time and evolution of the regulations may explain the difference in findings. It is also possible that the complexity of thermal modelling and split responsibility for achievement of compliance of Part L may underlie the issues with this area. The participants here followed those in the study by Bell and colleagues (2010) in describing a fragmented process, requiring specialist knowledge and a holistic understanding of the construction project but split across up to four different professional roles (architect, builder, SAP specialist, building control). As also noted in Bell et al. (2010), although specialists are required to produce a SAP calculation, these specialists usually do not have responsibility for checking compliance of the built form with the calculation. Visual inspection alone by a third party is insufficient to identify changes which take the model outside of compliance. It is therefore likely that there will be differences between the thermal model as designed and as built. A modified process is required, in which overall responsibility from design through modelling to on site checking is more fully integrated, with provision for effective independent verification. Enhancing the influence of building control through legislation on sustainability is not through regulatory change alone but also in the processes of application of the regulations. The limitations of the current study include the following. We argue that the BCS occupies a potentially influential role for sustainable construction but not that their position is unique. Indeed the evidence for a shared identity, body of knowledge and persuasive skills is likely to be available for many other construction professionals. Equally, claims are not made that all BCSs possess these skills. Any study which considers power and influence is subject to the methodological challenge described by Lukes (2005): if power may be possessed but not necessarily deployed, how is empirical 
evidence to be collected? In particular, if influence is the process of driving the behaviour of others potentially without their recognition, how may evidence of influence be collected? In this study, evidence was gathered from 21 practising BCSs and four representatives of professional bodies. Taking a critical stance, analysis found patterns of consistency across the themes of interest, with multiple examples consistent with theoretical insights and we propose that the evidence speaks to power and influence in the social role of the BCS. Future research could additionally seek to conduct studies involving perceptions of all project team members and, if possible, conduct observational studies. As mentioned above, investigating the forms and processes of power of other professionals in the project team would be valuable. Differential access to power and differential levels of influence characterize interactions in different contexts. Thus the dynamics of power between actors within a construction project will vary by size and type of project, the contractual arrangements, and the individual actors in the project team. Studies on different sizes and types of projects may show different patterns of influence. The effects of group identity and of status within the project team could illuminate further dimensions of power. Further exploration of the mechanisms of influence, including trust, could be particularly useful in offering practical insights.

\section{Conclusions}

The study offers novel insight into how building control surveyors perceive their role, and their potential influence in promoting sustainable construction, describing the power available to BCSs beyond that of the formal legitimate power inherent in their institutional position and some of the processes by which it is exercised. The participant BCSs readily identified the institutional power of their position but few showed awareness of other forms of influence which they used in everyday interactions.. In 
reality, the BCS's role is typically enacted through shared goals with the project team, through expert and informational power, and through mechanisms of influence such as persuasion and rapport. To strengthen the influence of BCSs, developing the shared group identity is key, and Hartenberger and colleagues (2013) suggest ways in which this could be accomplished. Greater awareness of their power may lead BCSs to experience greater self-efficacy, and sense of freedom and motivation to act. They may be less likely to feel that the regulations prevent them from influencing colleagues or that other professionals are more powerful. Finally, increased awareness of the power inherent in their role has the potential to enhance their ability to bring their knowledge and training to bear in order to further the progress of higher quality in construction in general and more sustainable construction in particular. The power and influence of the BCS may not always be observable but, as the opening quotation from Lukes suggests, it may nevertheless be deployed effectively to promote more sustainable construction. 


\section{References}

Baiche, B., Walliman, N., \& Ogden, R. (2006). Compliance with building regulations in England and Wales. Structural Survey, 24(4), 270-299.

Barbalet, J. M. (1985). Power and resistance. British journal of sociology, 36(4), 531-548.

Bell, M., Smith, M., \& Palmer, J. (2010). Review of the implementation of Part L 2006 (BD 2702). Retrieved from London: http://bit.ly/2rIozI4 [accessed 1.6.2017].

Boardman, B. (2007). Examining the carbon agenda via the $40 \%$ house scenario. Building Research and Information, 35(4), 363-378.

Brauer, M., \& Bourhis, R. Y. (2006). Social power. European journal of social psychology, 36, 601-616.

Braun, V., \& Clarke, V. (2006). Using thematic analysis in psychology. Qualitative Research in Psychology, 3(2), 77-101.

Bresnen, M. (2008). Reifying the client in construction management research? Alternative perspectives on a complex construct. In P. Brandon \& S.-L. Lu (Eds.), Clients driving innovation (pp. 49-57). Chichester: Blackwell Publishing.

Bresnen, M. (2013). Advancing a 'new professionalism': professionalization, practice, and institutionalization. Building research and information, 41(6), 735-741.

Bright, B. (2007). Whose job is it anyway? Fire and Safety Engineering, 14(9), 27-28. 
Chick, A., \& Micklethwaite, P. (2004). Specifying recycled: understanding UK architects' and designers' practices and experience. Design Studies, 25, 251-273.

Cialdini, R. (1993/2007). Influence: the psychology of persuasion. New York: Morrow.

Cox, C. S. J. (2006). Compliance with Part L1 of the 2002 Building Regulations (ED02302). Retrieved from http://bit.ly/1RZfYbz. [Accessed 1.6.2017]

DCLG. (2014). Building control performance standards. London: DCLG.

Dorrenbacher, C., \& Gammelgaard, J. (2016). Subsidiary initiative taking in multinational corporations: the relationship between power and issue selling. Organization studies, 37(9), 1249-1270.

Fellows, R., Liu, A., \& Storey, C. (2009). Values, power and performance on construction projects: a preliminary investigation. Paper presented at the 25th Annual ARCOM Conference, Nottingham, UK.

Fischer, J., \& Guy, S. (2009). Re-interpreting regulations: architects as intermediaries for low-carbon buildings. Urban Studies, 46(12), 25772594.

Fiske, S. T. (1993). Controlling other people: the impact of power on stereotying. American psychologist, 48(6), 621-628.

Fiske, S. T. (2001). Effects of power on bias: power explains and maintains individual, group, and societal disparities. In A. Y. Lee-Chai \& J. A. Bargh (Eds.), The use and abuse of power: multiple perspectives on the causes of corruption (pp. 181-193). Philadelphia, PA: Psychology Press. 
Fiske, S. T., \& Dépret, E. (1996). Control, interdependence and power: understanding social cognition in its social context. European review of social psychology, 7, 31-61.

Foucault, M. (1980). Power/knowledge: selected interviews and other writings. (C. Gordon Ed.). New York: Pantheon Books.

French, J. R. P., \& Raven, B. H. (1959). The bases of social power. In D. Cartwright (Ed.), Studies in social power (pp. 150-167). Ann Arbor, Michigan: Institute for Social Research.

Galinsky, A. D., Magee, J. C., Greunfeld, D. H., Whitson, J. A., \& Liljenquist, K. A. (2008). Power reduces the press of the situation: implications for creativity, conformity, and dissonance. Journal of personality and social psychology, 95(6), 1450-1466.

Geelhoed, E., Morrell, A., Caleb-Solly, P., \& Sun, M. (2012). Exploring the complexity of understanding, managing and marketing codes for sustainability in the current economic climate - issues for the small builder. Paper presented at the 3rd International Conference on Sustainability in Energy and Buildings, Marseilles, France.

Guinote, A., \& Vescio, T. K. (2010). The social psychology of power. New York: Guilford.

Haidt, J., \& Rodin, J. (1999). Control and efficacy as interdisciplinary bridges. Review of general psychology, 3(4), 317-337.

Hamza, N., \& Greenwood, D. (2009). Energy conservation regulations: impacts on design and procurement of low energy buildings. Buildings and environment, 44, 929-936. 
Hardy, C., \& Clegg, S. R. (1999). Some dare call it power. In C. Hardy \& S. R. Clegg (Eds.), Studying organization: theory and method (pp. 368-387). London: Sage.

Hartenberger, U., Lorenz, D., \& Lutzkendorf, T. (2013). A shared built environment professional identity through education and training. Building research and information, 41(1), 60-76.

Hughes, W., \& Hughes, C. (2013). Professionalism and professional institutions in times of change. Building research and information, 41(1), 28-38.

Imrie, R., \& Street, E. (2011). Architectural design and regulation. Chichester: Blackwell Publishing.

Keltner, D., Gruenfeld, D. H., \& Anderson, C. (2003). Power, approach and inhibition. Psychological review, 110, 265-284.

Killip, G. (2013). Products, practices and processes: Exploring the innovation potential for low-carbon housing refurbishment among small and medium-sized enterprises (SMEs) in the UK construction industry Energy Policy, 62, 522-530.

Lipsky, M. (1980/2010). Street-level bureaucrats: dilemmas of the individual in public services. New York: Russell Sage Foundation.

Lukes, S. (2005). Power: a radical view (2nd ed.). Basingstoke: Palgrave Macmillan.

Magee, J. C. (2009). Seeing power in action: the roles of deliberation, implementation, and action in inferences of power. Journal of experimental social psychology, 45, 1-14.

Melamed, D., \& Savage, S. V. (2013). Status, numbers and influence. Social forces, 91(3), 1085-1104. 
Murtagh, N., Roberts, A., \& Hind, R. (2016). The role of environmental sustainability in marketing of small architectural design practices. Construction management and economics, 34(4-5), 258-271.

Overbeck, J. R. (2010). Concepts and historical perspectives on power. In A. Guinote \& T. K. Vescio (Eds.), The social psychology of power (pp. 1945). New York: Guilford Press.

Pan, W., \& Garmston, H. (2012). Building regulations in energy efficiency: compliance in England and Wales. Energy Policy, 45, 594-605.

Raven, B. H. (1993). The bases of power: origins and recent developments. Journal of social issues, 49(4), 227-251.

Raven, B. H., Schwarzwald, J., \& Koslowsky, M. (1998). Conceptualizing and measuring a power/interaction model of interpersonal influence. Journal of Applied Psychology, 28(4), 307-332.

Reid, S. A., \& Ng, S. H. (1999). Language, power, and intergroup relations. Journal of social issues, 55(1), 119-139.

Russell, B. (1938). Power: A new social analysis. London: George Allen \& Unwin Ltd.

Simon, B., \& Oakes, P. (2006). Beyond dependence: an identity approach to social power and domination. Human relations, 59, 105=139.

Stryker, S., \& Burke, P. J. (2000). The past, present, and future of an identity theory. Social Psychology Quarterly, 63(4), 284-297.

Sun, M., Geelhoed, E., Caleb-Solly, P., \& Morrell, A. (2015). Knowledge and attitudes of small builders toward sustainable homes in the UK. Journal of Green Building, 10(2), 215-233. 
Tajfel, H., \& Turner, J. C. (1979). An integrative theory of intergroup conflict. In W. G. Austin \& S. Worchel (Eds.), The social psychology of intergroup relations (pp. 33-47). Monterey, CA: Brooks/Cole.

Turner, J. C. (2005). Explaining the nature of power: a three-process theory. European journal of social psychology, 35, 1-22.

Watkins, J. M., Mohr, B., \& Kelly, R. (2011). Appreciative inquiry: change at the speed of imagination (2nd ed.). San Francisco, CA: Pfeiffer.

Williams, K., \& Dair, C. (2007). What is stopping sustainable building in England? Barriers experienced by stakeholders in delviering sustainable development. Sustainable Development, 15(3), 135-147. 


\section{Appendix 1A Interview schedule - building control surveyors}

Stage-setting

How many building inspectors work here?

What is the workload like?

What type of projects do you inspect?

Do you offer any services beyond building inspection?

Could you describe a typical working week?

Is there a set number of inspections per project?

Building Inspector's Role

What would you say are the primary aims of a Building Inspector's role?

For you and your colleagues, are all building regulations of equal importance?

Individual Role

Looking at your own job and career,

How did you become a Building Inspector?

How do you keep up-to-date?

What motivates you in your job?

What do you enjoy about your job?

What is important to you in your work?

Best experience

Tell me about the best job you've been on, the one you're most proud of. What made it the best job for you?

Strengths

What do you think you do well in your job?

What skills or characteristics do you respect in your colleagues?

The industry and sustainability

What does sustainability in construction mean to you? 
What do you see as your role in environmentally sustainable construction?

\section{Concluding}

In an ideal world, how could Building Control make construction more sustainable?

\section{Appendix 1B Interview schedule - building control key informants}

Baseline

Could you outline for me the role of your organisation with regard to Building Control? What is your role in the organisation?

Sector

When did the change happen to allow Approved Inspectors alongside LABC?

How do people become Building Inspectors?

Do Approved Inspectors/Local Authority Building Control tend to offer other services, in addition to inspection?

Aims, objectives and influence

What would you say is the primary aim of the role of Building Control?

How does Building Control contribute to the construction industry?

How influential are Building Inspectors? Should Building Control be more influential? If so, how could they become more influential?

\section{Strengths}

What makes a good Building Inspector?

What are the strengths of the Building Control sector? 


\section{Sustainability}

What does sustainability in construction mean to you?

What do you see as the role of Building Control in improving environmentally sustainable construction?

In an ideal world, how could Building Control contribute more to greater environmental sustainability in building? 